Published in final edited form as:

JAMA Intern Med. 2018 October 01; 178(10): 1426-1427. doi:10.1001/jamainternmed.2018.4366.

\title{
Pharmaceutical Industry Marketing of Opioid Products to Physicians and Subsequent Opioid Prescribing
}

\author{
Scott E. Hadland, MD, MPH, MS ${ }^{1,2}$, Magdalena Cerdá, DrPH, MPH ${ }^{3}$, Brandon D. L. Marshall, \\ $\mathrm{PhD}^{4}$ \\ 1.Grayken Center for Addiction and Department of Pediatrics, Boston Medical Center, One Boston \\ Medical Center Place, Boston, MA 02118 \\ 2. Boston University School of Medicine, Division of General Pediatrics, Department of Pediatrics, \\ 88 East Newton Street, Vose Hall Room 322, Boston, MA, 02118 \\ 3.Department of Emergency Medicine, School of Medicine, University of California at Davis, 2315 \\ Stockton Boulevard, Sacramento, CA, 95817 \\ 4.Brown University School of Public Health, Department of Epidemiology, 121 South Main Street, \\ Providence, RI, USA, 02912
}

\section{MeSH Keywords:}

Opioids; Drug Industry; Non-Medical Use of Prescription Drugs; Prescriptions; Drug Overdose

In response to Ippolito and Veuger, although our study did not establish a cause and effect relationship, our work provides support for a causal link between pharmaceutical industry marketing and opioid prescribing by physicians. ${ }^{1}$

First, in order to establish temporality between exposure and outcome, we lagged physician opioid prescribing from marketing by one year. This allowed us to ensure that prescribing changes occurred after marketing was received, thus reducing the likelihood of reverse causality. Analyses also adjusted for prior prescribing behaviors, which likely confound the relationship between marketing and subsequent opioid prescribing.

Second, our findings are consistent with other research showing that physicians who receive pharmaceutical industry payments prescribe more of the medications being marketed..$^{2-4}$ Third, like other studies, ${ }^{2,4}$ we found a 'dose-response' association between marketing and prescribing, with each additional meal associated with greater subsequent prescribing.

Send correspondence to: Scott E. Hadland, MD, MPH, MS, Grayken Center for Addiction, Boston Medical Center, Department of Pediatrics, Boston University School of Medicine, 88 East Newton Street, Vose Hall, Room 322, Boston, MA, 02118, Phone:

617-414-3681, Fax: 617-414-3679, scott.hadland@bmc.org.

Contributors

Dr. Hadland conducted the literature review and wrote the first draft of the manuscript. All authors contributed to and have approved the final manuscript.

Conflict of Interest Statement

The authors have no conflicts of interest to disclose. 
It is unlikely that pharmaceutical companies would invest so heavily in direct-to-physician marketing if it did not increase or at least maintain current levels of prescribing. Even in the event of reverse causality - that is, that pharmaceutical companies market heavily to physicians who already frequently prescribe opioids (presumably to maintain their own prescribing levels and/or influence other prescribers in their practices)—-there remains the public health question of whether such a practice is appropriate in midst of an opioid overdose epidemic initially fueled in part by the availability of prescription opioids.

Ippolito and Veuger suggest that regulations limiting marketing from pharmaceutical companies would prevent physicians from receiving important information from manufacturers. Manufacturers may indeed offer information on appropriate opioid prescribing. Such information, however, is readily available from other sources, such as medical professional organizations and governmental bodies, and advocates have long argued that physicians should receive education from sources other than the pharmaceutical industry. ${ }^{5}$ The experience of academic medical centers that have limited marketing to physicians and trainees suggests that such restrictions reduce the influence of manufacturers on prescribing behaviors as intended. ${ }^{6}$

Legislation to limit industry payments to physicians is under discussion, and some pharmaceutical companies are voluntarily reducing opioid marketing. Much attention has been paid to speaker fees and other payments of larger value. Our finding that the provision of industry-sponsored meals may also influence physician prescribing underscores the importance of limiting the number of marketing interactions with physicians, not just the value of payments.

\section{Acknowledgments}

Role of Funding Source

Dr. Hadland was supported by the Thrasher Research Fund Early Career Award, the Academic Pediatric Association Young Investigator Award, the Loan Repayment Program Award L40 DA042434 (NIH/NIDA), and K23 DA045085 (NIH/NIDA). Dr. Cerdá was supported by R01 DA039962 (NIH/NIDA).

\section{References}

1. Hernán MA. The C-Word: Scientific Euphemisms Do Not Improve Causal Inference From Observational Data. Am J Public Health. 2018;108(5):616-619. doi:10.2105/AJPH.2018.304337. [PubMed: 29565659]

2. Yeh JS, Franklin JM, Avorn J, Landon J, Kesselheim AS. Association of Industry Payments to Physicians With the Prescribing of Brand-name Statins in Massachusetts. JAMA Intern Med. 2016;176(6):763. doi:10.1001/jamainternmed.2016.1709. [PubMed: 27159336]

3. DeJong C, Aguilar T, Tseng C-W, Lin GA, Boscardin WJ, Dudley RA. Pharmaceutical IndustrySponsored Meals and Physician Prescribing Patterns for Medicare Beneficiaries. JAMA Intern Med. 2016;176(8):1114-1122. doi:10.1001/jamainternmed.2016.2765. [PubMed: 27322350]

4. Fleischman W, Agrawal S, King M, et al. Association between payments from manufacturers of pharmaceuticals to physicians and regional prescribing: cross sectional ecological study. BMJ. 2016;354:14189. [PubMed: 27540015]

5. Tabas JA, Baron RB. Commercial funding of accredited continuing medical education. BMJ. 2012;344:e810. [PubMed: 22344304] 
6. Larkin I, Ang D, Steinhart J, et al. Association Between Academic Medical Center Pharmaceutical Detailing Policies and Physician Prescribing. JAMA. 2017;317(17):1785-1795. doi:10.1001/ jama.2017.4039. [PubMed: 28464141] 